\title{
Work in Progress: Utilizing Change Strategies and Chemical Process Safety Resources to Incorporate Process Safety Education in the Unit Operations Courses in Public and Private Universities
}

\section{Dr. Tracy L. Carter, Northeastern University}

Tracy Carter earned her $\mathrm{PhD}$ in the Chemical Engineering department at Northeastern University in the summer of 2018 and is currently an instructor in the Unit Operations Laboratory at NU. She earned the M.S. degree in 1998 and the B.S. degree in 1993 from Northeastern University. Dr. Carter previously worked in the biotechnology field for CytoTherapeutics, designing medical devices using membrane cell encapsulation. She resides just outside of Boston, MA with husband, son, twin daughters and three cats. She is active in her community and is passionate about safety education.

\section{Dr. Sarah A. Wilson, University of Kentucky}

Sarah Wilson is a lecturer in the Department of Chemical and Materials Engineering at the University of Kentucky. She completed her bachelor's degree at Rowan University in New Jersey before attending graduate school for her PhD at the University of Massachusetts in Amherst, MA. Sarah conducted her thesis research on the production of the anti-cancer compound Paclitaxel (Taxol) through the use of plant cell cultures from the Taxus Yew Tree. Throughout her time at Rowan and UMass, she developed a passion for undergraduate education. This passion led her to pursue a career as a lecturer, where she could focus on training undergraduate chemical engineering students. She has been teaching at UK since 2015 and has taught Fluid Mechanics, Thermodynamics, Computational Tools and the Unit Operations Laboratory. She is especially interested in teaching scientific communication and integration of process safety into the chemical engineering curriculum.

\section{Prof. Samira Azarin}

Samira Azarin is an Assistant Professor of Chemical Engineering and Materials Science at the University of Minnesota. She earned her B.S. in chemical engineering from the Massachusetts Institute of Technology in 2006 and went on to receive a Ph.D. in chemical engineering from the University of WisconsinMadison in 2011.

\section{Dr. Janie Brennan, Washington University in St. Louis}

Janie Brennan is a Lecturer of Energy, Environmental \& Chemical Engineering at Washington University in St. Louis. She earned her Ph.D. in Chemical Engineering from Purdue University in 2015. Her primary focus is on the application of research-based teaching methods in engineering education.

Amy J. Karlsson, University of Maryland

Amy J. Karlsson is an assistant professor in the Department of Chemical and Biomolecular Engineering at the University of Maryland - College Park. She received her BS in chemical engineering from Iowa State University and her PhD in chemical engineering from the University Wisconsin - Madison. At the University of Maryland, she has taught Separations, Unit Operations, and Protein Engineering and enjoys mentoring students of all levels in research focused on protein and peptide design.

\section{Dr. Christopher James Barr, University of Michigan}

Dr. Christopher Barr is the Instructional Laboratory Supervisor in the Chemical Engineering Department at University of Michigan. He obtained his Ph.D. at University of Toledo in 2013 and is a former Fellow in the N.S.F. GK-12 grant "Graduate Teaching Fellows in STEM High School Education: An Environmental Science Learning Community at the Land-Lake Ecosystem Interface". His main responsibilities are supervising and implementing improvements to the undergraduate labs. In Fall 2017, he was a lecturer for the Chemical Engineering Laboratory II. He also holds positions on the departmental Safety Committee and Undergraduate Program Committee. 


\section{Work in Progress: Utilizing change strategies and chemical process safety resources to incorporate process safety education in the unit operations courses in public and private universities}

\section{Introduction}

Chemical process safety education is necessary to reduce the number of chemical process safety incidents. In the past six years alone, there have been 40 fatalities and greater than 237 injuries reported in 20 different incidents investigated by the Chemical Safety and Hazard Investigation Board (CSB) [1]. The CSB is an independent federal agency that analyzes the root causes of incidents that occur at industrial facilities and gives feedback to the regulation and enforcement agencies. These investigations are not a comprehensive list of incidents, but they do identify the root causes that need to be addressed and indicate the need for process safety education.

The ABET (the program accrediting organization) chemical engineering program criteria require safety hazards to be addressed in the chemical engineering curriculum. Incorporating chemical process safety into the curriculum can been approached using two methods. The first is to create a new course. This approach enables students to focus on process safety exclusively for a semester, but it requires the entire curriculum to be restructured to fit in a new course and still maintain the same credit limit. Altering the overall curriculum structure in this way would also mean that content from other courses will need to be removed. The second method to approach process safety education is to integrate the relevant concepts into the current curriculum (for example, by integrating into the unit operations (UO) laboratory). Integration requires significantly more coordination, but it does not require a full curriculum restructure.

To support departments in identifying what specifically needs to be added, the Safety and Chemical Engineering Education (SAChE) Committee suggested eight learning outcomes that would meet the ABET program criteria [2]. To determine which outcomes are currently being taught in the UO laboratory, the curricula from six different universities were analyzed using the eight Chemical Process Safety learning outcomes recommended by SAChE [3]. The results of that study showed that process safety is minimally covered in the UO laboratory, and that other aspects of process safety are not covered even at the wider curriculum level.

To create the necessary curricular change, a recent model suggests four different strategies can be used independently or collectively to create change in higher education. These strategies are 1. policy, 2. shared vision, 3. curriculum and pedagogy, and 4. reflective teachers [4].

In both the chemical engineering program criteria as well as some of the required outcomes, ABET mentions a need to understand hazards and safety concepts associated with chemical and biological processes. This emphasis is an example of the type of (1) policy needed to support the necessary curricular changes. Utilizing the strategy of (2) shared vision, six different faculty members from six different universities (public and private as well as research- and teachingfocused), identified the need and desire to incorporate chemical process safety into their chemical engineering UO Laboratory. Based on the previous work, three of the eight SAChE outcomes were identified as minimally covered and also relevant to UO laboratory: 
5. The graduate should be familiar with the major regulations that impact the safety of chemical plants.

7. The graduate should be reasonably proficient with at least one hazard identification procedure.

8. The graduate should have an introduction to the process of hazard evaluation and risk assessment.

Therefore, these three outcomes were targeted for development of two of the Henderson model strategies within UO laboratories, (3) curriculum and pedagogy and (4) reflective teachers.

\section{Methods}

As a first step towards improving the chemical process safety curriculum and pedagogy in the UO laboratory, the authors chose to assess numerous freely-available resources relating to both chemical engineering generally, as well as process safety specifically [5-11]. These resources were evaluated for pedagogical utility as listed below, as well as the coverage of the three specified SAChE outcomes. Resources requiring a fee or other cost to students (e.g., the IChemE Safety Centre [12]) were not considered due to a higher barrier for implementation. Since pedagogical "utility" can encompass many factors, the authors chose to examine each resource for the following:

1. What depth of knowledge does the resource cover for each of the three selected SAChE outcomes, as indicated by a Bloom's taxonomy level? [13]

2. Is the resource designed to be stand-alone or would it require instructor mediation?

3. What is the potential to be reused across multiple course modules throughout a term?

4. Does the resource involve active engagement by the student (e.g., worksheets) or is it simply a passive communication of content (e.g., video)?

5. Does the resource include built-in learning assessment tools (e.g., quiz)?

6. Does the resource have a strong industry perspective illustrating a "real-world" connection?

7. Is the resource relevant to other chemical engineering core courses?

8. What is the estimated time required for students and/or faculty to use or implement?

9. What are some basic pros and cons for implementation?

The results of the evaluation are presented in Table 1. For the purposes of this paper, only those products most directly related to the desired outcomes and UO lab were included. Notably, two of the most comprehensive chemical engineering pedagogical resources, LearnChemE [14] and the AIChE Concept Warehouse [15], were evaluated but not included in the table due to a lack of coverage of the three process safety topics explored in this paper. It is understood by the authors, however, that process safety-related Concept Tests are currently in development for the AIChE Concept Warehouse [16].

\section{Analysis of Resources}

To gain a better understanding of the resources available for integration of regulations, hazard identification procedures, and hazard/risk assessment into a UO laboratory, an analysis of freely available resources was performed. Seven resources were identified that contain process safety content relevant to this analysis, and the characteristics of these resources are detailed in Table 1. 
Resource Name ${ }^{4}$

\section{Description of Process Safety Materials}

AIChE/CCPS/SAChE Multiple course options, each with video/lecture with

Certificate Program [5] quizzes. Can earn a certificate for each course.

\section{SAChE Lab Course Products [6]}

Project Risk Analysis Materials to teach a project risk analysis (procedure) and (PRA) implement it in the UO lab. Includes a presentation to introduce students to the concepts and process, a manual for faculty, and blank risk assessment tables.

\begin{tabular}{lllllllllll|lll} 
Hazard-specific & Materials to introduce specific types of hazards and how to & N/A & 1 & N/A & S & O & P & N & N & Y & Varies & Varies
\end{tabular} materials $\quad$ mitigate them. Materials vary for different hazards, but can include lecture slides, case studies, or laboratory experiment.

Safety in the Series of videos developed via a collaboration between

Chemical Process Michigan Tech and BASF to introduce students to industria

Industries laboratory and process safety. Includes instructor's guide and study guide for students.

Detailed hazard information;

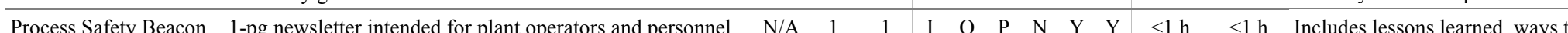
[7] Each newsletter focuses on a process safety incident, the cause and lessons learned. Specific strategies for management of change, risk identification are listed.

CCPS Faculty Workshops for faculty to demonstrate implementation of

Workshop [8] process safety in an industrial setting. Sponsored/hosted by industry, and facilitated by ChE faculty.

\begin{tabular}{llllll|lllllllllll} 
Chemical Safety Board & An independent federal agency which investigates industrial & 1 & 2 & 2 & $\mathrm{I}$ & $\mathrm{R}$ & $\mathrm{P}$ & $\mathrm{N}$ & $\mathrm{Y}$ & $\mathrm{Y}$ & $<4 \mathrm{~h}$ & Varies & Original source documents -
\end{tabular}

(CSB) [9] chemical accidents. Each investigated incident includes either a full report, case study, or safety bulletin, and many include a video.

tailorable to course design; full reports include discussions of

\begin{tabular}{ll|lll|lllllllllll} 
Process Safety Across & Builds upon CSB videos with tutorials and teaching & N/A & 3 & 4 & S & R & A & N & Y & Y & $<1 \mathrm{~h}$ & $<1 \mathrm{~h}$ & Teaches NFPA/BowTie risk
\end{tabular}

the ChE Curriculum resources targeted at faculty and students.

(SafeChE) [10]

Dow Safety Academy Teas

[11]

Series of safety-related videos ( 5-10 min each) developed by Dow Chemical. Also offers sample document templates (e.g., Lab Hazard Trigger Card, Safe Operation Card)
Easy to implement, can be done outside of class; ELA 950/952 courses address multiple outcomes Focused on UO lab courses

All materials (including slides) downloadable; integrates hazard \& risk analysis; analysis processes similar to industry covers hazard ID and control; good background for faculty

Highlights relevance of lab safety to industrial safety; students can watch on own time; industrial safety terms and procedures

ncludes lessons learned, ways to prevent future incidents; short (one
page), available in many languages

Registration/food/hotel free; see how industry approaches safety; get materials for safety course regulatory findings courses, incl. student worksheets

\section{Cons}

Time-intensive outside of class; course integration requires instructor certificate completion Requires free $\mathrm{SAChE}$ account

Not all materials editable; some aspects not clearly explained; not all topics can be experienced in class

Focus on single hazards; some material challenging to incorporate into UO lab course

Videos older (1988); no video transcripts available

Single topic covered per newsletter

Must pay for travel costs; large volume of information can be difficult to parse/apply

Format/length/content varies by incident; volume of information can difficult to parse/apply; focuses on results, not process

Ignores other assessment methods; no discussion of regulations

Most of content targeted at lab, not process, safety; information often relevant worksheets industry perspective may add impact superficial due to brevity

${ }^{1}$ Bloom's Taxonomy Level is listed as a number: 1 = Knowledge, 2 = Comprehension, $3=$ Application, $4=$ Analysis, $5=$ Synthesis, $6=$ Evaluation, N/A-Resource does not cover the outcome.

${ }^{2}$ A reusable resource is one that provides a framework for teaching a concept (vs. a set of materials to teach a single topic).

${ }^{3}$ Activity-based resources include materials such as worksheets or interactive experiments, while passive resources only have students read or watch materials.

${ }^{4}$ The AIChE Concept Warehouse and Learn ChemE resources were also assessed but were not included in the table due to minimal/no coverage of the three target SAChE Outcomes. 
The resources were prepared by a variety of organizations and take many different formats. The American Institute of Chemical Engineers (AIChE)/Center for Chemical Process Safety (CCPS)/SAChE Certificate Program [5] is an online process safety curriculum with certificates to document completion. The SAChE Lab Course products [6] include several independent resources: (1) Project Risk Analysis (PRA) materials for implementing a qualitative risk analysis of UO laboratory experiments, (2) hazard-specific materials on relevant process hazards, and (3) Safety in the Chemical Process Industries videos detailing process safety information at an industrial site. In the Process Safety Beacon [7], each one-page newsletter analyzes a different process safety incident, including mitigation strategies. The CCPS Faculty Workshops [8] are industry-hosted workshops to teach chemical engineering faculty about process safety at an industrial site. The Chemical Safety Board (CSB) [9], an independent federal agency, details investigations of industrial incidents, often including videos. Using these videos, Process Safety Across the ChE Curriculum (SafeChE) [10] has developed process safety-themed tutorials and pedagogical tools, including application of the National Fire Protection Association (NFPA) hazard assessment. Finally, the Dow Safety Academy [11] is a series of videos produced by Dow Chemical that present safety topics from an industrial perspective. While the analysis in this paper focused on currently available resources, some resources are in the process of being updated (SAChE certificates, AIChE Concept Warehouse) to improve process safety content [5, 16], so their content and process-safety relevance will need to be reevaluated when the updates are complete.

Of the seven resources, many were found suitable as stand-alone resources for a student audience, whereas others require the instructor to lead the students through using the resource. One resource (CCPS Faculty Workshop) was designed with the specific purpose of educating an instructor. The resources suitable for stand-alone use by students are all online resources that can easily be incorporated into a UO or process safety course. Of these, three resources (AIChE/CCPS/SAChE Certificate Program, several SAChE Lab Course Products, and the Dow Safety Academy) include educational videos that can be assigned outside of a course for independent learning. The Process Safety Beacon and Chemical Safety Board (CSB) resources highlight industrially relevant process safety incidents but require further instructor guidance/activity development for incorporation into the curriculum. Process Safety Across the Chemical Engineering Curriculum (SafeChE) has addressed this for the CSB materials by developing tutorials and teaching resources for instructors based on the materials found on the CSB website. The PRA found in the SAChE Lab Course products requires an instructor to initially teach the procedure to students, though the students can then apply it throughout the UO laboratory course. Only one resource, the AIChE/CCPS/SAChE Certificate Program, includes built-in assessments; therefore, instructors need to develop their own assessments of student learning for other resources. Additionally, about half of the resources incorporate activities into the modules to aid in student learning (AIChE/CCPS/SAChE Certificate Program, SAChE Lab Course Products PRA, SafeChE, and the Dow Safety Academy), while the remaining resources involve solely passive learning (videos, reading material, etc.)

Of the resources analyzed, the CCPS Faculty Workshops are a unique resource targeted to faculty members. These industry-sponsored workshops provide an opportunity for instructors to learn about industrially relevant and company-specific process safety. Attending a workshop will give instructors the necessary background to confidently discuss process safety in the UO 
laboratory. However, no specific materials for implementation into the UO laboratory are provided, so the instructors must reframe the material learned into content suitable for the laboratory.

Overall, most of the resources provide low-level learning based on Bloom's taxonomy [13] for the outcomes analyzed, and any higher-level learning materials would have to be developed by the instructor. From a content perspective, there is significant coverage of hazard identification procedures and slightly less on hazard evaluation/risk assessment. Of these, several reach higher levels of Bloom's taxonomy. Notably, the SAChE Lab Course Products PRA and the SafeChE site reached the analysis level. These resources include tools for students to identify hazards in UO experiments and analyze their associated risk. Only two resources (CSB and CCPS Faculty Workshops) had coverage of regulations, with each only reaching the knowledge level of Bloom's taxonomy, indicating a significant hole in available resources to teach this outcome.

The analysis of these resources was used to summarize the strengths of publicly available process safety tools, while identifying opportunities to improve their utility. One highlight of the analysis was that almost all of the resources incorporate industrially relevant process safety incidents, with some mentioning strategies that can be used to prevent future incidents. However, few provide instruction on how to apply or teach students these strategies, particularly in a UO laboratory context. In a UO laboratory course, clear opportunities exist to link the passive instructional content to activities that would allow students to practice hazard identification and risk analysis strategies. Moving forward, developing a shared resource with guidelines and recommendations for incorporating these process safety tools into the UO laboratory could ease the workload associated with curriculum integration. Additionally, the lack of coverage on regulation will continue to be a challenge, so resource development and implementation in the UO laboratory should be a focus in this area.

\section{Conclusions and Recommendations}

Creating the necessary chemical process safety educational changes is difficult; however, the Henderson model for creating effective change allows for progress through implementation of (1) policy, (2) shared vision, (3) curriculum and pedagogy, and (4) reflective teaching. Many resources are available for incorporating safety education in the chemical engineering undergraduate curriculum. This study was aided by the assembly of a team of instructors to efficiently collect and assess these resources, some of which are quite extensive, as it would be challenging for a single instructor to do so. Some of the resources were more focused on laboratory safety than chemical process safety, and notably the majority provided low-level learning based on Bloom's taxonomy. Despite the easy availability of these resources, this analysis has revealed that Unit Operations instructors will need to develop their own resources to directly integrate much of this content into their courses or to develop activities that are higher on the Bloom's taxonomy scale.

Accordingly, the next step is to leverage the collaborative efforts of this multi-institution group of instructors to incorporate some of this content, such as risk quantification tables and an incident reporting structure, into their courses and assess their efficacy in enhancing students' preparedness in chemical process safety. This study has identified notable gaps in the available 
educational materials. For instance, the lack of resources related to regulations and the focus on descriptions of incidents and vocabulary as opposed to higher-level pedagogical content with corresponding assessment tools. As a result, there is a need for the development of resources that could more readily enable instructors to incorporate effective process safety content into their unit operations courses.

\section{References}

[1] U. S. Chemical Safety and Hazard Identification Board, "Investigations," U. S. Chemical Safety and Hazard Identification Board, 2018. [Online].

Available: https://www.csb.gov/investigations/current-investigations/. [Accessed: 07-Oct2018].

[2] Safety and Chemical Engineering Education, "SAChE Recommendations for ABET Safety Content in Chemical Engineering," 2010. [Online].

Available: http://sache.org/SACHEGuidelinesForABET.pdf. [Accessed: 14-Oct-2018].

[3] T. L. Carter, S. M. Azarin, J. Brennan, E. Hill, A. J. Karlsson, 2018, June, "Work in Progress: Identifying Current Standards and Addressing the Need for Further Process Safety Education in Unit Operations Courses," in 2018 ASEE Annual Conference \& Exposition, Salt Lake City, Utah, June 23-27, 2018. [Online]. Available: https://peer.asee.org/31290. [Accessed: 14-Oct-2018].

[4] C. Henderson, A. Beach, and N. Finkelstein, "Facilitating change in undergraduate STEM instructional practices: An analytic review of the literature," Journal of Research in Science Teaching, vol. 48, no. 8, pp. 952-984, 2011.

[5] American Institute of Chemical Engineering (AICHE) Center for Chemical Process Safety (CCPS), Safety and Chemical Engineering Education (SAChE) Certificate Program, 2017. [Online]. Available: https://www.aiche.org/ccps/community/technologicalcommunities/safety-and-chemical-engineering-education-sache/certificate-program. [Accessed: 30-Jan-2019].

[6] Safety and Chemical Engineering Education (SAChE), SAChE - Course List, n.d. [Online]. Available: http://sache.org/view_course_list.asp?id=8. [Accessed: 18-Dec-2018].

[7] Safety and Chemical Engineering Education (SAChE), "Process Safety Beacon", Safety and Chemical Engineering Education Program, 2007. [Online]. Available: http://sache.org/beacon/products.asp. [Accessed: 30-Jan-2019].

[8] American Institute of Chemical Engineering (AICHE) Center for Chemical Process Safety (CCPS), CCPS Faculty Workshops | CCPS | Center for Chemical Process Safety, 2017. [Online]. Available: https://www.aiche.org/ccps/resources/conferences/events/facultyworkshops. [Accessed: 30-Jan-2019]. 
[9] Chemical Safety Board (CSB), U.S. Chemical Safety and Hazard Investigation Board | CSB, 2006. [Online]. Available: https://www.csb.gov/. [Accessed: 14-Dec-2018].

[10] H. S. Fogler, "Process Safety Across the Chemical Engineering Curriculum", SafeChemE Home, 2017. [Online]. Available: http://umich.edu/ safeche/. [Accessed: 14-Dec-2018].

[11] The Dow Chemical Company, "Dow Lab Safety Modules", Lab Safety Academy | Science \& Sustainability | Dow Corporate, 2013. [Online]. Available: https://corporate.dow.com/en-us/science-and-sustainability/lab-safety. [Accessed: 30-Jan2019].

[12] Institution of Chemical Engineers (IChemE), Safety Centre - IChemE, 2018. [Online]. Available: https://www.icheme.org/knowledge/safety-centre/. [Accessed: 18-Jan-2019].

[13] B.S. Bloom (ed.). Taxonomy of Educational Objectives. Vol. 1: Cognitive Domain. New York: McKay, 1956.

[14] University of Colorado Boulder Department of Chemical \& Biological Engineering, LearnChemE - Educational Resources for Engineering Courses, 2006. [Online]. Available: http://www.learncheme.com/home. [Accessed: 14-Dec-2018].

[15] American Institute of Chemical Engineering (AICHE) Education Division, AIChE Concept Warehouse, 2011. [Online]. Available:

http://jimi.cbee.oregonstate.edu/concept_warehouse/CW.php. [Accessed: 30-Jan-2019].

[16] B. Vaughen, "An approach for teaching process safety risk engineering and management control concepts using AIChE's web- based concept warehouse", Process Safety Progress, December 2018. [Online]. Available: https://doi.org/10.1002/prs.12010. [Accessed: 30-Jan2019]. 